\title{
Research on Classroom Teaching Mode Reform of Automobile Service Engineering Program
}

\author{
Xiao Mi \\ School of Mechanical and Vehicle Engineering \\ LinYi University \\ Linyi, China \\ mixiao@lyu.edu.cn
}

\begin{abstract}
To improve the talent training quality of automobile service engineering program and meet the requirements of the engineering education accreditation, this research carried out a thorough classroom teaching mode reform. We analyzed the drawbacks and limitations of the traditional teaching mode and designed a whole new seven-step classroom teaching process. We applied several teaching ideas and methods, including flipped classroom, theory and practice integration, group teaching and composite teaching to the new teaching process. The difficulties and solutions in the implementation process is also discussed in this paper. From the job market feedback, most of the students who have graduated from the program are proved to be qualified to enter careers in marketing, operation, and maintenance in the field of automobile service engineering technology. It shows that the classroom teaching mode reform in this research is effective, and the desired objectives are achieved.
\end{abstract}

Keywords-Teaching reform; Flipped classroom; Theory and practice integration; Group teaching

\section{INTRODUCTION}

To meet the demands of the engineering education accreditation, the traditional classroom teaching mode of the automobile service engineering program has to be reformed thoroughly. In the traditional classroom teaching mode, it is the teacher's lecturing that takes most of the teaching time, the students only accept and answer what teachers teach and ask, and are mainly under a passive learning position. Moreover, the disconnection between theory and practice of instructional design is universal in the traditional classroom teaching mode [1]. The teaching contents should be also updated to meet the needs of the latest automobile service engineering technology. Therefore, the new classroom teaching process is designed and several teaching ideas and methods, including flipped classroom, theory and practice integration, group teaching and composite teaching are applied to the classroom teaching process [2]. From the job market feedback, most of the students who have graduated from the program are proved to be qualified to enter careers in marketing, operation, and maintenance in the field of automobile service engineering technology.

\section{Classroom Teaching Process Design}

The new classroom teaching process is designed and it is mainly composed of seven teaching steps as shown in figure 1. These steps are students preview, classroom questioning, question explanation, group discussion, teacher's lecturing, group practice and classroom testing. All the teaching steps are performed during class time except the step of student preview. Several teaching ideas and methods are applied on the classroom teaching process

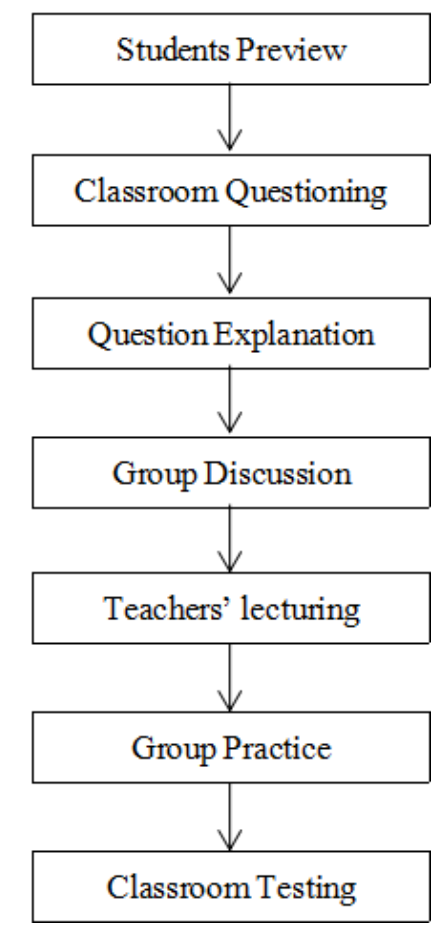

Fig. 1. Classroom teaching process flow

\section{A. The step before class}

The first step is students preview and it is performed in one week before the class. The teacher's activity is to send the learning resources, such as guided learning plan, teaching courseware, teaching video, to the students to guide them to cope with the preview assignment in group and assess their preview perform. The students' activity is to preview the learning resources in the guided learning plan, teaching 
courseware and teaching video with the help of learning objectives, key and difficult points and learning methods which is included in the guided learning plan. The students may learn individually, discuss in group or go to the workshop to operate the equipment. They also have to finish the essay questions, assignment and multiple choice questions and discuss their answers in group. Then they feed the common questions back to teacher.

\section{B. Steps during class}

- The class is performed in the workshop. It begins after about five minutes of teaching preparation. The teacher's activity is to perform the safety education, check the attendance and distribute tools, vehicles or engines to the groups. The students' activity is to report the attendance and check the tools.

- The classroom questioning is the first step of the class. The teacher's activity is to play the teaching videos and ask questions towards the actual vehicles and devices to assess the students' performance. The students' activity is to recall the preview content and answer the questions.

- The step of question explanation is mainly to solve the common questions that all the groups feed back to teacher during the preview. The teacher's activity is to collect these questions and let the students from other groups try to answer and then make the final comment and summary for every question. The students' activity is to express their opinion, listen to the teacher's comment and summary and solve their questions.

- The step of classroom discussion is to help the students to think the deeper question which is related to the key and difficult points. The teacher's activity is to provide two or three questions for the students to discuss in group and participate in their discussion. And adjust the teaching emphasis of the next step based on the students' performance. The students' activity is to think and discuss these questions and consult the teacher to get the personalized guidance.

- The step of teacher's lecturing is adjusted based on the students' performance in the previous steps. The teacher's activity is to summarize the discussion of all groups and deliver a lecture in detail of the students' noticeable problems and key and difficult points of the lesson. The students' activity is to listen to the teacher's lecture and enhance their understanding of these questions. Most of the questions of the student are solved after this step.

- The step of group practice is to combine the theory with practice. The teacher's activity is to distribute the worksheet, explain the assignment requirement and demonstrate the operation procedure. Then the teacher instructs the students to finish the worksheet in group and assess the performance of every group. The students' activity is to have technology exchanges and cooperate with their teammates and accomplish the assignment.
- The last step is classroom testing. The teacher's activity is to summarize all of the teaching content and comment on the practice performance of different group and organize an in-class quiz. The students' activity is to listen the teacher's comment, reflect the learning process and take the in-class quiz.

- The secondary learning could be organized after class if it is necessary. The teacher's activity is to mark the inclass quiz and record the points. And inform the group or student who fail the quiz to go back to the workshop and learn the content again until they pass the test. The students' activity is that some groups or students take the secondary learning and test after class.

\section{TEACHING MODE REFORM}

The teaching mode reform is carried out by performing the new teaching process design. And several teaching ideas and methods are applied in the teaching process design, such as flipped classroom, theory and practice integration, group teaching and composite teaching. Several problems are encountered during these new teaching ideas and methods are being operated. And the factors that affect the teaching effectiveness of these new teaching ideas and methods must be analyzed.

\section{A. Flipped classroom}

Flipped classroom is an instructional strategy and a type of blended learning that reverses the traditional learning environment by delivering instructional content, often online, outside of the classroom. It changes activities, including those that may have conventionally been considered homework, into the classroom. In a flipped classroom, students watch online courses, combine with online discussions, or carry out assignment at home and engage in concepts in the classroom with the guidance of the teacher [3].

In the conventional model of classroom teaching, the teacher is usually the central focus of a lesson and the only disseminator of teaching content in the class period. The teacher responds to problems when students defer to the teacher for guidance and feedback. In a classroom with a conventional style of teaching, almost all the lessons are focused on an explanation of teaching content by the way of lecturing. Student engagement in the conventional teaching mode is usually limited to learning activities in which students work independently or in small groups on an application task designed by the teacher. Class discussions are also usually lead by the teacher, who controls the flow of the conversation. In most cases, this pattern of teaching also involves giving students the task of reading from a textbook or practicing a concept by working on a problem set, for instance, outside school.

The flipped classroom is to shift the teaching process to a learner-centered model and therefore the students could explore the topics in greater depth during the class time. And the class time is used to make more meaningful learning activities, while educational technologies such as teaching videos are used to 'deliver content' before the class[4]. In a flipped classroom, 'content delivery' may be accomplished by 
several ways. Usually, video lessons prepared by the teacher or third parties are used to deliver content, although online combined with discussions, digital research, and text readings may be used.

However, there are also some critics argue that the flipped classroom teaching mode has some disadvantages for both students and teachers.

For students, we call the problem is the 'financial divide'. Not all families can afford to provide a laptop for the student to study, and thus access to computers or video-viewing technology outside of the school environment is not possible for all students. This model of instruction may put undue pressure on some families as they attempt to gain access to videos outside of school hours.

Additionally, some students may face the huge difficulties due to their developing personal motivation. In a self-directed, home learning environment students who do not have enough motivation and self-management ability required to keep ontask with independent learning may fall rapidly behind their peers.

Another problem is that the flipped classroom leads to increased computer time in an era where adolescents already spend too much time in front of computer screens. Inverted models that rely on computerized videos do contribute to this challenge, particularly if videos are long. So all the teaching clips must be made less than twenty minutes.

Additionally, flipped classrooms that rely on videos to deliver instruction suffer some of the same challenges as traditional classrooms. Students may not learn best by listening to a lecture, and watching instructional videos at home is still representative of a more traditional form of teaching. Critics argue a constructivist approach would be more beneficial.

Teachers may find challenges with this model as well. Increased preparation time is initially likely needed, as creating high quality videos requires teachers to contribute significant time and effort outside of regular teaching responsibilities. Additional funding may also be required to procure training for teachers to navigate computer technologies involved in the successful implementation the inverted model [5].

To make the flipped classroom more effectively, several polices could be carried out from our teaching practice experience.

- Establishment of a flipped classroom research team. The university or school need to combine all the resources together to establish a professional flipped classroom research team. All the team members have their own responsibility of different courses and share and exchange the respective research results to achieve the objective of improving the flipped classroom effectiveness [6].

- The reasonable teacher evaluation mechanism. The teaching mode reform has to be included in the teacher's academic assessment. It provides the teacher's motivation to improve flipped classroom effectiveness.
What's more, the flipped classroom has to be used with other teaching methods to overcome its disadvantages mentioned above.

\section{B. Theory and practice integration}

Theory and practice integration means that the barrier between the theory teaching and practice teaching in the conventional mode is broken and the theory and practice learning mix together organically. The classroom is moved to the workshop rather than the conventional classroom. The typical classroom in the new teaching mode is as shown in figure 2 .

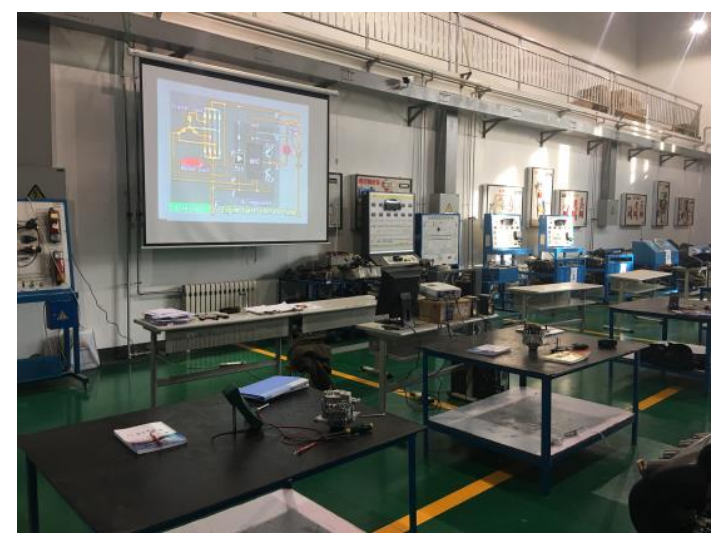

Fig. 2. The classroom used in new teaching mode

As an application-oriented university, the objective of talents training for the automobile service engineering program is to ensure that most of the students who have graduated from the program are qualified to enter careers in marketing, operation, and maintenance in the field of automobile service engineering technology. Therefore, the cultivation of innovative entrepreneurial ability is of great importance. In the conventional teaching mode, the students' learning process is divides into two separate types which are theory knowledge learning and practice knowledge learning. The barrier between the two learning processes is very clear. It limits the cultivation of the students' practice ability. The factors that cause that disadvantage are as follows.

- The lack of the textbooks that are based on task-driven and theory-practice integration teaching methods. The conventional textbooks are usually written by the order of putting theory knowledge first and practice knowledge following. These textbooks are not suitable for the new teaching mode. Therefore, the whole new textbooks need to be written to meet the demands of the new task-driven and theory-practice integration teaching mode.

- The lack of the teaching process design that are based on task-driven and theory-practice integration teaching methods. Therefore, in the new teaching process design, the step of group practice combines the theory with practice. The teacher distributes the worksheet, explains the assignment requirement and demonstrates the operation procedure. Then the teacher instructs the students to finish the worksheet in group and assess the 
performance of every group. The students have technology exchanges and cooperate with their teammates and accomplish the assignment. The theorypractice organically integration is accomplished.

- The lack of the reasonable course evaluation. In the conventional teaching mode, the course evaluation is mainly based on the marks of the final examination. The final assessment has difficulties in reflecting and motivating the students' learning process. Therefore, in the new teaching process design, the assessment is performed during the whole learning process by both the teacher and the students. And the secondary learning could be organized after class if it is necessary. The teacher marks the in-class quiz and record the points. And inform the group or student who fail the quiz to go back to the workshop and learn the content again until they pass the test.

\section{Group teaching}

The group teaching means that the students study in group during the whole teaching process. It is the requirement of the talents training objective. The students must master the teamwork and technical communication skills. During the group teaching mode, the students discuss and coordinate with each other and also assess each other.

However, the individual assessment and the whole group assessment must combine together to evaluate both their independent ability and cooperation ability.

\section{CONCLUSION}

The classroom teaching mode reform of automobile service engineering program is performed thoroughly to meet the demands of the engineering education accreditation. Several teaching ideas and methods, including flipped classroom, theory and practice integration, group teaching and composite teaching are applied to the classroom teaching process. From the job market feedback, most of the students who have graduated from the program are proved to be qualified to enter careers in marketing, operation, and maintenance in the field of automobile service engineering technology. The teaching reform is effective, and the desired objectives are achieved.

\section{REFERENCES}

[1] Liu Bao, Li Zhengang, Ruan Boxing. "College Classroom Teaching Mode Reform Based on Engineering Education Accreditation," J. Heilongjiang Researches on Higher Education, 2017, pp.157-160 (In Chinese).

[2] Wang Wenjing. "Learning-oriented Synthetic Classroom Teaching Model: Teaching Model Reform in China,” J. Journal of Beijing Normal University (Social Science Edition), 2012, pp. 18-24 (In Chinese).

[3] Bill Tucker. "The Flipped Classroom,” J. Education Next, 2012, pp.1415.

[4] Catherine H. Crouch, E. Mazur. "Peer Instruction: Ten Years of Experience and Results," J. American Journal of Physics, 2001, pp.973975.

[5] Gerstein, J. "The flipped classroom model: A full picture," 2011.

[6] Hein, E.G." Constructivist Learning Theory," C. CECA conference, 1991. 